\title{
Phytochemical characterization and bioactive properties of Osyris quadripartita Salzm. ex Decne. from Algeria
}

\author{
Wahiba Rached ${ }^{\mathrm{a}, \mathrm{b}, \mathrm{c}}$, Ricardo C. Calhelha ${ }^{\mathrm{a}}$, Ângela Fernandes ${ }^{\mathrm{a}}$, Ana Maria Carvalho ${ }^{\mathrm{a}}$, \\ Malika Bennaceur $^{\mathrm{b}, \mathrm{c}}$, Abderrazak Marouf ${ }^{\mathrm{d}}$, Lillian Barros ${ }^{\mathrm{a},{ }^{*}}$, Celestino Santos-Buelga ${ }^{\mathrm{e}}$, \\ Isabel C.F.R. Ferreira ${ }^{a}{ }^{*}$
}

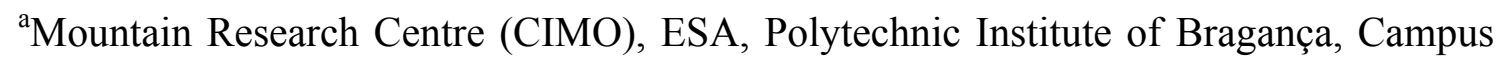
de Santa Apolónia, 5300-253 Bragança, Portugal.

${ }^{b}$ Laboratory of Plant Biochemistry and Natural Products, Department of Biology, Faculty of nature and life sciences, University Ahmed Ben Bella Oran 1, 1524 ELM Naouer 31000 Oran, Algeria.

${ }^{c}$ Laboratory of Research in Arid Areas (LRZA), PO Box 32, El Alia Bab-Ezzouar, Algiers 16111, Algeria

${ }^{\mathrm{d}}$ Center University Salhi Ahmed, Naama, Algeria.

${ }^{e}$ GIP-USAL, Faculty of Pharmacy, Universityof Salamanca, Campus Miguel de Unamuno, 37007 Salamanca, Spain.

*Authors to whom correspondence should be addressed (e-mail: iferreira@ipb.pt telephone +351-273-303219; fax +351-273-325405; e-mail: lillian@ipb.pt telephone $+351-273-303903)$. 


\begin{abstract}
Medicinal plants are sources of bioactive compounds with recognized beneficial effects on human health. An example is Osyris quadripartita, also known as Osyris lanceolata which is known for its traditional therapeutic properties in some African countries. The aim of the present study was to evaluate the antioxidant (free radicals scavenging activity, reducing power and lipid peroxidation inhibition), anti-inflammatory (inhibition of NO production in lipopolysaccharide-stimulated RAW 264.7 macrophages) and cytotoxic (in a panel of human tumor cell lines and in non-tumor porcine liver primary cells) properties of $O$. quadripartita, providing a phytochemical characterization of its aqueous extracts and different organic fractions, by using highperformance liquid chromatography coupled to diode array detection and electrospray ionisation mass spectrometry (HPLC-DAD-ESI/MS). Twenty-eight individual phenolic compounds were identified: fifteen flavan-3-ols, six flavones, four flavonols, two phenolic acids and one flavanone derivative. The main abundant compounds in the ethyl acetate fraction were $(+)$-catechin and procyanidin dimer B1 (EC-4,8-C). Quercetin-3$O$-rutinoside was the major compound in both n-butanol fraction and crude aqueous extract. In most of the samples and assays the antioxidant activity was higher than the one revealed by the positive control Trolox, being the highest antioxidant activity observed in the ethyl acetate fraction. The same fraction also showed the highest inhibition of NO production and the highest cytotoxicity against MCF-7 and NCI-H460 cell lines. This study highlights the potential of $O$. quadripartita fractions rich in phenolic compounds to be used in pharmaceutical and cosmetic fields.
\end{abstract}

Keywords: Osyris quadripartita; phenolic compounds; antioxidant; anti-inflammatory; cytotoxic properties 


\section{Introduction}

The over production of reactive oxygen species (ROS) beyond the antioxidant capacity of biological systems leads to oxidative stress which is involved in various inflammatory processes and diseases including cancer (Kashfi, 2009; Carocho and Ferreira, 2013a). The major group of secondary metabolites, phenolic compounds might contribute to prevent these chronic diseases due to their strong antioxidant properties (Ozsoy et al., 2008; Carocho and Ferreira, 2013b). Phenolic compounds act as free radical scavengers and ROS quenchers, being also able of decomposing peroxides, chelating transition metals and inhibiting enzymes (e.g., xanthine oxidase and cyclooxygenase) involved in the production of reactive species (Pokorny et al., 2001; Fraga, 2007; Halliwell, 2008; Embuscado, 2015).

With the increased interest in natural bioactive compounds, health professionals interested in holistic practices and research scientists are carrying out experimental trials to confirm the in vitro results obtained with phytochemicals in the prevention of many diseases (Tiwari, 2001; Halliwell, 2006, 2009). Meanwhile, it is important to explore the Plantae kingdom (e.g., medicinal plants) in order to find alternative sources of antioxidant molecules that could be used in chemoprevention of inflammatory processes and chronic diseases.

Osyris quadripartita Salzm. Ex Decne. is a synonymy of Osyris lanceolata Hochst. \& Steud (Santalaceae). It is an hemiparasitic shrub or small tree from the Mediterranean and tropical regions (hot and dry ones), ranging from Southern Europe (Portugal and Spain), northern, eastern and southern Africa, through Arabia, to Indian subcontinent, China, Myanmar, Thailand and Laos (Quezel and Santa, 1963; Singh et al., 2005; Fern et al. 2016). In Algeria, this species is recognized as Madjad. Osyris genus is widely 
used in traditional medicine as anti-diarrhea, anti-malaria and antifungal agents, and to treat kidney diseases and cancer (Semenya and Maroyi, 2012; Masevhe et al., 2015).

The dried leafs and roots of $O$. quadripartita are used in aqueous oral preparations for treatment of cancer and the leaf infusion has emetic properties being used to cure diarrhea and eye infection (Chhabra et al., 1991; Kelbessa and Nagappan, 2014). Its anti-inflammatory, antibacterial, antifungal and antimalarial activities have been previously described (Geyid et al., 2005; Van Vuuren and Viljoen, 2006; Mulaudzi et al., 2011; Mulaudzi et al., 2013; Girma, 2015). Furthermore, there are very few reports in literature regarding the phytochemical composition whitin this species. Nonetheless, Yeboah et al., (2010) reported the presence of dihydroagarofuran sesquiterpenes and triterpenes. Other Osyris species have been investigated regarding their chemical characterization, highlighting the presence of glycosylated flavonoids (kaempferol-3-Orutinoside) in O. alba (Iwashina et al., 2008) and sesquiterpenes in O. tenuifolia (Kreipl and Konig, 2004).

The aim of the present study was to evaluate the antioxidant, anti-inflammatory and cytotoxic properties of $O$. quadripartita, providing a phytochemical characterization of its aqueous extracts and different organic fractions.

\section{Materials and Methods}

\subsection{Plant material}

The leaves of Osyris quadripartita Salzm.Ex Decne. (wild tea; local name: Madjad) were harvested at west of Algeria (Oran) in August 2014. The botanical identification of the plant was confirmed by Professor Marouf Abderrazak from University Center Naama (Algeria). The fresh material was oven-dried at $40{ }^{\circ} \mathrm{C}$ during $48 \mathrm{~h}$ and then reduced to a fine powder $(\sim 40$ mesh $)$. 


\subsection{Standards and reagents}

HPLC-grade acetonitrile was obtained from Merck KgaA (Darmstadt, Germany). Formic and acetic acids were purchased from Prolabo (VWR International, France). Butanol (99\%) was from Lab-Scan and ethyl acetate (99.8\%) was from Fisher Scientific (Lisbon, Portugal). Trolox (6-hydroxy-2,5,7,8-tetramethylchroman-2-carboxylic acid) was purchased from Sigma (St. Louis, MO, USA). Phenolic compound standards were purchased from Extrasynthèse (Genay, France). 2,2-Diphenyl-1-picrylhydrazyl (DPPH) was obtained from Alfa Aesar (Ward Hill, MA, USA). Foetal bovine serum (FBS), Lglutamine, hank's balanced salt solution (HBSS), trypsin-EDTA (ethylenediaminetetraacetic acid), penicillin/streptomycin solution $(100 \mathrm{U} / \mathrm{mL}$ and 100 mg/mL, respectively), RPMI-1640 and DMEM media were from Hyclone (Logan, Utah, USA). Acetic acid, ellipticine, sulforhodamine B (SRB), trypan blue, trichloroacetic acid (TCA) and Tris were from Sigma Chemical Co. (St Louis, MO USA). Water was treated in a Milli-Q water purification system (TGI Pure Water Systems, Greenville, SC, USA).

\subsection{Extraction procedure}

The dried and powdered leaves of $O$. quadripartita were extracted three times by heat reflux with distilled water $10 \%(\mathrm{w} / \mathrm{v})$ during 30 minutes followed by filtration. The filtered solution obtained was lyophilized (Gardiner, NY, USA) to dryness. The obtained aqueous extract (10 g) was then solubilized in distilled water and further partitioned using solvents with increasing polarity (chloroform, ethyl acetate and nbutanol) by performing successive liquid-liquid extractions. 
The following extracts and fractions were used in the subsequent assays: crude aqueous extract, and ethyl acetate and butanol fractions. The residues were re-dissolved in water: methanol $(80: 20, v: v)$ for phenolic compounds characterization, methanol $(5 \mathrm{mg} / \mathrm{mL})$ for antioxidant activity evaluation, and water $(8 \mathrm{mg} / \mathrm{mL})$ for anti-inflammatory and cytotoxicity assays. In the bioactivity evaluation assays, the stock solutions were further diluted and tested.

\subsection{Phenolic compounds characterization}

Phenolic compounds were determined by high-performance liquid chromatography (HPLC, Hewlett-Packard 1100, Agilent Technologies, Santa Clara, CA, USA) as previously described by the authors (Roriz et al., 2014). Separation was achieved with a Waters Spherisorb S3 ODS-2 $\mathrm{C}_{18}(4.6 \times 150 \mathrm{~mm}$ i.d., $3 \mu \mathrm{m})$ column thermostatted at 35 ${ }^{\circ} \mathrm{C}$, using a gradient elution, with (A) $0.1 \%$ formic acid in water, (B) acetonitrile. Detection was performed using a double online detection with a diode array detector (DAD) using $280 \mathrm{~nm}$ and $370 \mathrm{~nm}$ as preferred wavelengths and in a mass spectrometer

(MS) (API 3200 Qtrap, Applied Biosystems, Darmstadt, Germany). Phenolic compounds were identified by comparing their retention time, UV-vis and mass spectra with those obtained from standard compounds when available, or were tentatively identified comparing these data with the information reported in the literature. For quantitative analysis, a calibration curve for each available phenolic standard (apigenin$C$-glucoside, (+)-catechin, $p$-coumaric acid, (-)-epicatechin, naringenin, kaempferol-3$O$-rutinoside, quercetin-3-O-rutinoside, quercetin-3-O-glucoside and protocatechuic acid) was constructed based on the UV signal at maximum wavelength 280 or $370 \mathrm{~nm}$. Compounds for which no standard was available were quantified by the curve of other 
standard compound of the same phenolic group. The results were expressed in mg per $g$ of extract or fraction.

\subsection{In vitro antioxidant activity assays}

2.4.1. DPPH radical scavenging activity. This methodology was performed using an ELX800 Microplate Reader (Bio-Tek). The reaction mixture in each one of the 96-wells consisted of one of the different concentrations of the extracts $(30 \mu \mathrm{L})$ and methanolic solution $(270 \mu \mathrm{L})$ containing DPPH radicals $\left(6 \times 10^{-5} \mathrm{~mol} / \mathrm{L}\right)$. The mixture was left to stand for 60 min in the dark. The reduction of the DPPH radical was determined by measuring the absorption at $515 \mathrm{~nm}$. The radical scavenging activity (RSA) was calculated as a percentage of DPPH discoloration using the equation: $\%$ RSA $=$ $\left[\left(A_{D P P H}-A_{S}\right) / A_{D P P H}\right] \times 100$, where $A_{S}$ is the absorbance of the solution when the sample extract has been added at a particular level and $\mathrm{A}_{\mathrm{DPPH}}$ is the absorbance of the DPPH solution (Roriz et al., 2014).

2.4.2. Reducing power. This methodology was performed by using the microplate reader described above. The different concentrations of the extracts $(0.5 \mathrm{~mL})$ were mixed with sodium phosphate buffer $(200 \mathrm{mmol} / \mathrm{L}, \mathrm{pH} 6.6,0.5 \mathrm{~mL})$ and potassium ferricyanide $(1 \% \mathrm{w} / \mathrm{v}, 0.5 \mathrm{~mL})$. For each concentration, the mixture was incubated at 50 ${ }^{\circ} \mathrm{C}$ for $20 \mathrm{~min}$, and trichloroacetic acid $(10 \% \mathrm{w} / \mathrm{v}, 0.5 \mathrm{~mL})$ was added. The mixture $(0.8$ $\mathrm{mL})$ was poured into the 48 -wells, as also deionized water $(0.8 \mathrm{~mL})$ and ferric chloride $(0.1 \% \mathrm{w} / \mathrm{v}, 0.16 \mathrm{~mL})$, and the absorbance was measured at $690 \mathrm{~nm}$ (Roriz et al., 2014).

2.4.3. Inhibition of $\beta$-carotene bleaching. $\beta$-Carotene $(2 \mathrm{mg})$ was dissolved in chloroform $(10 \mathrm{~mL})$ and $2 \mathrm{~mL}$ of this solution were pipetted into a round-bottom flask. 
After the chloroform was removed at $40{ }^{\circ} \mathrm{C}$ under vacuum, linoleic acid (40 mg), Tween 80 emulsifier $(400 \mathrm{mg})$, and distilled water $(100 \mathrm{~mL})$ were added to the flask with vigorous shaking. Aliquots $(4.8 \mathrm{~mL})$ of this emulsion were transferred to different test tubes containing different concentrations of the extracts $(0.2 \mathrm{~mL})$. The tubes were shaken and incubated at $50{ }^{\circ} \mathrm{C}$ in a water bath. As soon as the emulsion was added to each tube, the zero time absorbance was measured at $470 \mathrm{~nm}$. $\beta$-Carotene bleaching inhibition was calculated using the following equation: (absorbance after $2 \mathrm{~h}$ of assay/initial absorbance) $\times 100$ (Roriz et al., 2014).

2.4.4. TBARS formation inhibition. Porcine brains were obtained from official slaughtering animals, dissected, and homogenized with a Polytron in ice cold Tris-HCl buffer $(20 \mathrm{mM}, \mathrm{pH} 7.4)$ to produce a $1: 2 \mathrm{w} / \mathrm{v}$ brain tissue homogenate which was centrifuged at $3000 \mathrm{~g}$ for $10 \mathrm{~min}$. An aliquot $(100 \mu \mathrm{L})$ of the supernatant was incubated with the different concentrations of the samples solutions $(200 \mu \mathrm{L})$ in the presence of $\mathrm{FeSO}_{4}(10 \mathrm{mM} ; 100 \mu \mathrm{L})$ and ascorbic acid $(0.1 \mathrm{mM} ; 100 \mu \mathrm{L})$ at $37^{\circ} \mathrm{C}$ for $1 \mathrm{~h}$. The reaction was stopped by the addition of trichloroacetic acid $(28 \% \mathrm{w} / \mathrm{v}, 500 \mu \mathrm{L})$, followed by thiobarbituric acid (TBA, 2\%, w/v, $380 \mu \mathrm{L}$ ), and the mixture was then heated at $80{ }^{\circ} \mathrm{C}$ for $20 \mathrm{~min}$. After centrifugation at $3000 \mathrm{~g}$ for $10 \mathrm{~min}$ to remove the precipitated protein, the colour intensity of the malondialdehyde (MDA)-TBA complex in the supernatant was measured by its absorbance at $532 \mathrm{~nm}$. The inhibition ratio (\%) was calculated using the following formula: Inhibition ratio $(\%)=[(\mathrm{A}-\mathrm{B}) / \mathrm{A}] \times 100 \%$, where $\mathrm{A}$ and $\mathrm{B}$ were the absorbances of the control and the sample solutions, respectively (Roriz et al., 2014). 
2.4.5. Determination of $E C_{50}$ values. The sample concentrations providing $50 \%$ of antioxidant activity or 0.5 of absorbance $\left(\mathrm{EC}_{50}\right)$ were calculated from the graphs of antioxidant activity percentages (DPPH, $\beta$-carotene/linoleate and TBARS assays) or absorbance at $690 \mathrm{~nm}$ (reducing power assay) against sample concentrations. Trolox was used as positive control.

\subsection{In vitro anti-inflammatory assays}

2.5.1. Cells culture. The mouse macrophage-like cell line RAW 264.7 was cultured in DMEM medium supplemented with $10 \%$ heat-inactivated foetal bovine serum (FBS), glutamine and antibiotics at $37{ }^{\circ} \mathrm{C}$ under $5 \% \mathrm{CO}_{2}$, in humidified air. For each experiment, cells were detached with a cell scraper. In the experiment cell density of $5 \times 10^{5}$ cells $/ \mathrm{mL}$ was used, and the proportion of dead cells was less than $5 \%$ according to the Trypan blue dye exclusion test. Cells were seeded in 96-well plates at 150,000 cells/well and allowed to attach to the plate overnight. Subsequently, cells were treated with the various concentrations of each sample for $1 \mathrm{~h}$. Dexamethasone $(50 \mu \mathrm{M})$ was used as a positive control for the experiment. The following step was the stimulation with LPS $(1 \mu \mathrm{g} / \mathrm{mL})$ for $18 \mathrm{~h}$. The effect of all the tested samples in the absence of LPS was also evaluated, in order to observe if they induced changes in Nitric oxide (NO) basal levels. In negative controls, no LPS was added. Both extracts and LPS were dissolved in supplemented DMEM (Corrêa et al., 2015).

2.5.2. Nitric oxide determination. For the determination of nitric oxide, a Griess Reagent System kit was used, which contains sulphanilamide, N-(1napthyl)ethylenediamine hydrochloride (NED) and nitrite solutions. A reference curve of nitrite (sodium nitrite $100 \mu \mathrm{M}$ to $1.6 \mu \mathrm{M} ; \mathrm{y}=0.0063 \mathrm{x}+0.1318 ; R^{2}=0.9999$ ) was 
prepared in a 96-well plate. The cell culture supernatant $(100 \mu \mathrm{L})$ was transferred to the plate and mixed with sulphanilamide and NED solutions, 5-10 minutes each, at room temperature. The nitric oxide produced was determined by measuring the absorbance at $540 \mathrm{~nm}$ (microplate reader ELX800 Biotek), and by comparison with the standard calibration curve (Corrêa et al., 2015). The results were expressed in $\mathrm{EC}_{50}$ values $(\mu \mathrm{g} / \mathrm{mL})$, which correspond to the sample concentration providing $50 \%$ of inhibition of nitric oxide (NO) production.

\subsection{Cytotoxicity assays}

2.6.1. In human tumor cell lines. Four human tumor cell lines were used: MCF-7 (breast adenocarcinoma), NCI-H460 (non-small cell lung cancer), HeLa (cervical carcinoma) and HepG2 (hepatocellular carcinoma). Cells were routinely maintained as adherent cell cultures in RPMI-1640 medium containing 10\% heat-inactivated FBS and $2 \mathrm{mM}$ glutamine (MCF-7, NCI-H460, HepG2 and HeLa cells) at $37{ }^{\circ} \mathrm{C}$, in a humidified air incubator containing 5\% $\mathrm{CO}_{2}$. Each cell line was plated at an appropriate density $\left(7.5 \times 10^{3}\right.$ cells/well for MCF-7 and NCI-H460 or $1.0 \times 10^{4}$ cells/well for HeLa and HepG2) in 96-well plates. The sulforhodamine B assay was performed according to a procedure previously described by the authors (Corrêa et al., 2015). Ellipticine was used as positive control and the results were expressed as $\mathrm{GI}_{50}$ values (sample concentration that inhibited $50 \%$ of the net cell growth) in $\mu \mathrm{g}$ per $\mathrm{mL}$.

2.6.2. In non-tumor cells. A cell culture was prepared from a freshly harvested porcine liver obtained from a local slaughter house, and it was designed as PLP2. Briefly, the liver tissues were rinsed in hank's balanced salt solution containing $100 \mathrm{U} / \mathrm{mL}$ penicillin and $100 \mu \mathrm{g} / \mathrm{mL}$ streptomycin, and divided into $1 \times 1 \mathrm{~mm}^{3}$ explants. Some of 
these explants were placed in $25 \mathrm{~cm}^{2}$ tissue flasks in DMEM medium supplemented with $10 \%$ FBS, $2 \mathrm{mM}$ nonessential amino acids and $100 \mathrm{U} / \mathrm{mL}$ penicillin and 100 $\mu \mathrm{g} / \mathrm{mL}$ streptomycin, and incubated at $37{ }^{\circ} \mathrm{C}$ with a humidified atmosphere containing $5 \% \mathrm{CO}_{2}$. The medium was changed every two days. Cultivation of the cells was continued with direct monitoring every two to three days using a phase contrast microscope. Before confluence was reached, cells were subcultured and plated in 96well plates at a density of $1.0 \times 10^{4}$ cells/well, and cultivated in DMEM medium with $10 \% \mathrm{FBS}, 100 \mathrm{U} / \mathrm{mL}$ penicillin and $100 \mu \mathrm{g} / \mathrm{mL}$ streptomycin. Ellipticine was used as positive control (Corrêa et al., 2015).

\subsection{Statistical analysis}

Three samples were used for each extract/fraction and all the assays were carried out in triplicate. The results are expressed as mean values and standard deviations (SD). The results were analyzed using one-way analysis of variance (ANOVA) followed by Tukey's HSD test with $\alpha=0.05$. This treatment was carried out using the SPSS v. 22.0 program.

\section{Results and discussion}

\subsection{Phenolic compounds}

Twenty eight individual phenolic compounds: fifteen flavan-3-ols, six flavones, four flavonols, two phenolic acids and one flavanone derivatives were detected and tentatively identified in the aqueous extract, ethyl acetate and butanolic fractions of $O$. quadripartita leaves (Table 1). An example of the phenolic profile of O. quadripartita leaves ethyl acetate fraction, recorded at 280 and $370 \mathrm{~nm}$, is shown in Figure 1. To the 
best of our knowledge this is the first report fully characterizing the phenolic composition in O. quadripartita leaves.

The largest group of compounds found in both fractions and extract were flavan-3-ol derivatives. Compounds 8 and 12 were positively identified as (+)-catechin and (-)epicatechin, according to their retention time, mass and UV-vis characteristics by comparison with commercial standards. The remaining flavan-3-ols were identified as proanthocyanidins based on their pseudomolecular ions and $\mathrm{MS}^{2}$ fragmentation patterns. The analysis of the produced fragments provides information about the type elementary units and might also inform about their relative position in the proanthocyanidins oligomer. Mass spectra do not allow, however, establishing the position of the linkage between flavanol units (i.e., C4-C8 or C4-C6) nor differentiating between isomeric catechins (e.g., catechin/epicatechin). Compounds 3, 5, 9, 11, 14, 16 and 21 presented the same pseudomolecular ion $[\mathrm{M}-\mathrm{H}]^{-}$at $\mathrm{m} / \mathrm{z} 577$ and $\mathrm{MS}^{2}$ fragmentation patterns coherent with B-type (epi)catechin dimers. Characteristic product ions were observed at $m / z 451(-126 \mathrm{u}), 425(-152 \mathrm{u})$ and $407(-152-18 \mathrm{u})$, attributable to the HRF, RDA and further loss of water from an (epi)catechin unit, and at $m / z 289$ and 287 , that could be associated to the fragments corresponding to the lower and upper (epi)catechin unit, respectively (Santos-Buelga and González-Paramás, 2014). According to their elution behaviour, those compounds could be tentatively assigned to the different catechin (C) and epicatechin (EC) dimers linked through C4C8 or C4-C6 interflavan linkages. Thus, in RP-HPLC, procyanidins B3 (C-4,8-C) and B1 (EC-4,8-C) are expected to elute before (+)-catechin, and dimers B4 (C-4,8-EC) and B2 (EC-4,8-EC) before (-)-epicatechin (Santos-Buelga et al., 2003), so that they could be associated to peaks 3, 5, 9 and 11, respectively, identification that was also supported by comparison with our compound library. For their part, peaks 14, 16 and 21 can be 
assumed as C4-C6-linked dimers taking into account their later elution; based on their relative position in the chromatogram they could correspond to procyanidins B7 (EC4,6-C), B8 (C-4,6-EC) and B5 (EC-4,6-EC). The concentrations of these compounds in the samples seem coherent with those identities, since C4-C6-linked derivatives are usually less abundant than their C4-C8 counterparts (de Pascual-Teresa et al., 2000). Similarly, peaks $1,2,6,7$ and 19 (pseudomolecular ions $[\mathrm{M}-\mathrm{H}]^{-}$at $\mathrm{m} / z$ 865), can be assigned as B-type (epi)catechin trimers. In this case it is more difficult to anticipate a structure for the compounds, although oligomers are expected to elute earlier the greater the number of lower catechin sub-units (Santos-Buelga et al., 2003); at least peaks 1 and 2 might be speculated to correspond to trimers C-4,8-C-4,8-C (C2) and EC-4,8-C-4,8-C, the only ones that could be expected to elute before the dimer B3. In all cases, fragmentation patterns are coherent with those expected for such types of compounds, i.e., similar at those observed for proanthocyanidins dimers but with additional fragments from the alternative cleavages of different interflavan bonds.

Peak 10 presented a pseudomolecular ion $[\mathrm{M}-\mathrm{H}]^{-}$at $m / z 435$ with a $\mathrm{MS}^{2}$ fragment ion at 289 from the loss of $-146 \mathrm{u}$, indicating the loss of a rhamnoside moiety; the possibility of that moiety could correspond to a $p$-coumaroyl residue can be discarded since no maximum was observed in the UV spectrum around $310 \mathrm{~nm}$. The rest of $\mathrm{MS}^{2}$ fragments are coherent with (epi)catechin. The elution order of the compound suggested that it could derive from epicatechin since glycosylated derivatives should elute before their corresponding aglycones, so that it was tentatively identified as epicatechin- $O$ rhamnoside.

Compounds 13, 15, 17, 18, 22 and 23 presented pseudomolecular ions $[\mathrm{M}-\mathrm{H}]^{-}$at $\mathrm{m} / \mathrm{z}$ 593 or 563 , releasing $\mathrm{MS}^{2}$ fragment ions at $\mathrm{m} / \mathrm{z}$ at $473 \mathrm{and} /$ or 443 from the loss of 90 and $120 \mathrm{u}$, characteristic of $C$-glycosylated flavones. The loss of -120 u is typical of $C$ - 
attached hexoses, whereas that of $-90 \mathrm{u}$ is observed for $C$-attached pentoses and it is also usual in the case of $6-C$-hexoses but less common in the case of 8 - $C$-hexoses (Cuyckens and Claeys, 2004). The compounds were tentatively identified as apigenin glycosides owing to the observation of the ions at $\mathrm{m} / \mathrm{z} 383$ and 353 that might correspond to the aglycone plus residues of the sugars that remained linked to it (apigenin $+113 \mathrm{u}$ ) and (apigenin $+83 \mathrm{u}$ ), respectively (Ferreres et al., 2003). The fact that no relevant fragments derived from the loss of hexosyl $(-162 \mathrm{u})$ or pentosyl moieties $(-132 \mathrm{u})$ were detected suggested that sugars were not $O$-attached. These observations allowed the tentative identification of these compounds as apigenin-di- $C$ hexoside (compound 13) and apigenin- $C$-hexoside- $C$-pentoside (compounds 15, 17, 18 , 22 and 23). Schaftoside (apigenin-6-C- $\beta$-D-glucopyranoside- $8-C$ - $\alpha$-Larabinopyranoside), isoschaftoside (apigenin-6- $C$ - $\alpha$-L-arabinopyranoside- $8-\mathrm{C}-\beta-\mathrm{D}-$ glucopyranoside) and vicenin-2 (apigenin 6,8-di- $C$-glucoside) have been previously reported by Iwashina et al. (2008) in dried aerial parts and fruits of Osyris alba. Thus, an identity as vicenin-2 could be tentatively assumed for peak 13, although no assignment as schaftoside/isoschaftoside can be concluded for the other five compounds.

Peaks 4 and 24 were positively identified as protocatechuic acid and $p$-coumaric acid, respectively, according to their retention time, mass and UV-vis characteristics as compared with commercial standards. Comparison with standards also allowed identification of peaks 26,27 and 28 as quercetin-3-O-rutinoside, quercetin-3-Oglucoside and kaempferol-3-O-rutinoside, respectively, according to their retention time, mass and UV-vis characteristics by comparison with commercial standards. These three flavonols have been previously described in another Osyris species, such as Osyris alba (Iwashina et al., 2008). The pseudomolecular ion of compound $20\left([\mathrm{M}-\mathrm{H}]^{-}\right.$at $\mathrm{m} / \mathrm{z}$ 
755), releasing only one $\mathrm{MS}^{2}$ fragment at $\mathrm{m} / \mathrm{z} 301$, indicated that it corresponded to a quercetin derivative bearing two deoxyhexosyl and one hexosyl moieties, and that the three sugars were linked together. Since no information about the identity and location of the sugar moieties onto the aglycone could be obtained, the compound was tentatively assigned as quercetin- $O$-dideoxyhexosyl-hexoside.

Finally, compound $25\left([\mathrm{M}-\mathrm{H}]^{-}\right.$at $\left.m / z 433\right)$ presented an $\mathrm{MS}^{2}$ fragment ion at $m / z 271$ ($162 \mathrm{u}$ ) indicating the loss of a hexoside moiety from the aglycone, which was identified as the flavanone naringenin also based on its UV spectrum; thus, it was tentatively identified as naringenin- $O$-hexoside.

The ethyl acetate fraction presented the highest concentration in phenolic compounds, being $(+)$-catechin the most abundant compound. Aqueous extract and butanolic fraction presented similar contents of phenolic compounds, being quercetin-3-Orutinoside the main molecule present. Moreover, the phenolic profiles of all fractions and extracts presented similarities in their qualitative composition, although some differences were observed, especially in the ethyl acetate fraction, where no flavone derivatives where present.

\subsection{Antioxidant activity}

To evaluate the antioxidant activity of the samples, four assays normally used in herbs, beverages and biological fluids were selected. Those assays may be globally classified as electron-transfer (ET)-based assays (ferric reducing antioxidant power (FRAP) and the 2,2-diphenyl-1-picrylhydrazyl (DPPH) assays) and hydrogen atom transfer (HAT)based assays (TBARS and $\beta$-carotene bleaching inhibition assays) (Huang et al., 2005). The antioxidant activity of the crude aqueous extract and its ethyl acetate and butanol fractions was compared with the antioxidant standard Trolox. For the DPPH assay, the 
$\mathrm{EC}_{50}$ value basically represents the required concentration for an antioxidant to reach $50 \%$ of DPPH radical scavenging (Chen et al., 2013). Lower $\mathrm{EC}_{50}$ values are related with higher free radical scavenging activity of an antioxidant (Osman, 2011). The results for the DPPH assay revealed that all the extracts exhibited greater activity than Trolox $(42 \mu \mathrm{g} / \mathrm{mL})$, showing the highest activity the ethyl acetate fraction $(5 \mu \mathrm{g} / \mathrm{mL})$ followed by the butanol fraction $(10 \mu \mathrm{g} / \mathrm{mL})$ and the aqueous extract $(12 \mu \mathrm{g} / \mathrm{mL})$ (Table 2). The DPPH scavenging activity of an ethyl acetate fraction of $O$. quadripartita was previously analysed (but performing the assay in a spectrophotometer instead of microplates reader), being also higher than other aqueous extracts (Rached et al., 2010). This activity was attributed to plant metabolites such as flavonoids and other phenolic compounds (Araceli et al., 2003; Kulkarni et al., 2004; Krishnaiah et al., 2011).

The evaluation of the reducing power is based on the presence of reductants in the extracts that provoke the reduction of $\mathrm{Fe}^{3+} /$ ferricyanide complex to the ferrous form $\left(\mathrm{Fe}^{2+}\right)$. On the other hand, the complex $\mathrm{FeCl}_{3} / \mathrm{K}_{3} \mathrm{Fe}(\mathrm{CN})_{6}$ allows the evaluation of the polyphenols participating in the redox reaction (Chung et al., 2002; Amarowicz et al., 2004). The FRAP method showed that the ethyl acetate fraction also presented the highest reducing power $(2 \mu \mathrm{g} / \mathrm{mL})$, followed by the butanol fraction $(4 \mu \mathrm{g} / \mathrm{mL})$ and the crude aqueous extract $(6 \mu \mathrm{g} / \mathrm{mL})$. Once again, Trolox had lower reducing power than the tested samples $(41 \mu \mathrm{g} / \mathrm{mL})$ (Table 2).

The $\beta$-carotene/linoleic acid bleaching assay is based on the ability of the antioxidant to reduce the oxidation of linoleic acid and to inhibit the free radicals generated by the emulsion system like conjugated diene hydroperoxides arisen from linoleic acid oxidation (Koleva et al., 2002; Tepe et al., 2005). In this assay, the ethyl acetate fraction also showed the highest inhibition capacity, followed by the butanol fraction and the 
crude extract (3.4, 3.8 and $4.6 \mu \mathrm{g} / \mathrm{mL}$, respectively; Table 2$)$, presenting a $\beta$-carotene bleaching inhibition higher than Trolox.

The inhibition of formation of thiobarbituric acid (TBA) reactive substances (TBARS assay), using porcine brain as a real animal tissue, is usually employed as an indicator of the lipid oxidation process. In this assay, the malondialdehyde (MDA) reacted with TBA to form a pink MDA-TBA complex that is measured spectrophotometrically at 530-535 nm (Shahidi and Zhong, 2005). The oxidation of lipid peroxides leads to the formation of alkoxy and peroxy radicals as primary oxidation products, which in turn produce numerous secondary products such as carbonyl derivatives like MDA, which is formed as a result of the degradation of polyunsaturated fatty acids (Shahidi and Zhong, 2005). The MDA might produce DNA damage and has been found to be an important cause of several ageing diseases like cancer (Shinmoto et al., 1992; Liao et al., 2014). Again, the highest activity in the TBARS assay was exhibited by the ethyl acetate fraction $(1.3 \mu \mathrm{g} / \mathrm{mL})$, followed by the butanol fraction $(1.4 \mu \mathrm{g} / \mathrm{mL})$ and the aqueous extract $(2 \mu \mathrm{g} / \mathrm{mL})$, all of them greater than the activity showed by Trolox $(23 \mu \mathrm{g} / \mathrm{mL})$.

The solubility and extraction ability of polyphenols are highly dependent on the solvent, so that the differences observed in the antioxidant activity of the tested samples could be related with the use of different extraction solvents that certainly extracted compounds with different polarity. Actually, Çelik et al. (2010) reported the influence of the solvent and its polarity on the antioxidant behavior of phenolic compounds. In the same context, Singh et al. (2007) found different antioxidant activity in Acacia auriculiformis extracts prepared with solvents of increasing or decreasing polarity, which related to differences in the total phenolic contents and composition.

In our study, the antioxidant activity of the extract and its fractions might be related with their phenolic composition, which influences their capacity to scavenge free 
radicals and prevent lipid peroxidation (Yanishlieva-Maslarova, 2001; Gardi et al., 2015). The highest antioxidant activity exhibited by the ethyl acetate fraction could be related with its highest content in phenolic compounds $(504 \pm 5 \mathrm{mg} / \mathrm{g}$ extract; Table 1), in particular (+)-catechin, followed by procyanidin dimer B1 (EC-4,8-C). The butanol fraction showed a phenolic content similar to the aqueous crude extract, and both presented lower levels of flavan-3-ols than the ethyl acetate fraction, with quercetin-3$O$-rutinoside as the major flavonoid.

\subsection{Anti-inflammatory activity}

The anti-inflammatory activity of the crude aqueous extract and its ethyl acetate and butanol fractions was evaluated using lipopolysaccharide (LPS) activated mouse macrophage RAW 264.7 cells; dexamethasone was used as a known inhibitor of NO production (positive control). All the samples demonstrated significantly inhibition percentages with $\mathrm{EC}_{50}$ values ranging between 78 and $211 \mu \mathrm{g} / \mathrm{mL}$ (Table 2). The ethyl acetate fraction exhibited the highest activity. Several bioactive phytochemical components, among them phenolic compounds, could be contributing for the mentioned activity (Middleton and Kandaswami, 1992; Wang et al., 2014). The anti-inflammatory properties of the major compound present in the ethyl acetate fraction, $(+)$-catechin, were described by Marinovic et al. (2015), which gives support to its role in the bioactivity revealed by that fraction. The anti-inflammatory potential exhibited by the butanol fraction and aqueous extract could be related with the presence of quercetin and apigenin glycoside derivatives (Shen et al., 2002; Wang and Huang 2013).

\subsection{Cytotoxic properties}


The cytotoxic properties of the aqueous extract of $O$. quadripartita and its ethyl acetate and butanol fractions were tested against MCF-7 (breast adenocarcinoma), NCI-H460 (non-small cell lung cancer), HeLa (cervical carcinoma) and HepG2 (hepatocellular carcinoma) human tumor cell lines, and non-tumor cells (PLP2- porcine liver primary cells). Ellipticine was used as positive control and all the resultsare shown in Table 3.

HepG2, HeLa and MCF-7 were more susceptible to the tested samples than NCI-H460. Up to the maximal tested concentrations $\left(\mathrm{GI}_{50}>400 \mu \mathrm{g} / \mathrm{mL}\right)$, none of the samples showed toxicity against normal cells (PLP2). The highest inhibitory effects were observed with the aqueous extract for HepG2 and HeLa cell lines $\left(\mathrm{GI}_{50}=46\right.$ and 87 $\mu \mathrm{g} / \mathrm{mL}$, respectively). The ethyl acetate fraction presented the highest cytotoxic properties for MCF-7 and NCI-H460 cell lines (114 and $265 \mu \mathrm{g} / \mathrm{mL}$, respectively), which could be related with a higher concentration of favan-3-ols (Table 1), such as catechin and epicatechin derivatives (Rodgers and Grant, 1998; Delgado et al., 2009; Haza and Morales, 2011). However, this activity should not be attributed to individual compounds, but to synergisms among bioactive molecules present in the extract; this is evident in the aqueous extract which was more effective against cervical (HeLa) and hepatocellular (HepG2) carcinoma cell lines.

Overall, this study showed that phenolic compounds are present in the aqueous extract of O. quadripartita, as also in its ethyl acetate and n-butanol fractions. These preparations revealed antioxidant, anti-inflammatory and cytotoxic properties. The ethyl acetate fraction displayed the highest bioactivities, which were related to its higher content in favan-3-ols. Further studies are required in order to establish the mechanism of action, supporting the use of this plant in pharmaceutic or cosmetic fields. 


\section{Acknowledgements}

The authors are grateful to Foundation for Science and Technology (FTC, Portugal) for financial support to CIMO (Pest-OE/AGR/UI0690/2014), A. Fernandes (SFRH/BD/76019/2011), R.C. Calhelha (SFRH/BPD/68344/2010) and L. Barros (SFRH/BPD/107855/2015) grants. The authors also thank the University Oran 1, the University Abdelhamid Ibn Badis Mostaganem and the LRZA (Algeria) for financial support of this research work.

\section{References}

Amarowicz, R., Pegg, R.B., Rahimi-Moghaddamc, P., Barl B., Weil, J.A., 2004. Freeradical scavenging capacity and antioxidant activity of selected plant species from the Canadian prairies. Food Chem. 84, 551-562.

Araceli, S., Camen, R.M., Guillermo, R.S., 2003. Assessment of the anti-inflammatory activity and free radical scavenger activity oftiliroside. Eur. J. Pharmacol. 461, $53-61$.

Carocho, M., Ferreira, Ferreira, I.C.F.R., 2013b. The Role of Phenolic Compounds in the Fight Against Cancer - A Review. Anti-Cancer Agent. Med. Chem. 13, $1236-1258$.

Carocho, M., Ferreira, I.C.F.R., 2013a. A review on antioxidants, prooxidants and related controversy: natural and synthetic compounds, screening and analysis methodologies and future perspectives. Food Chem. Toxicol. 51, 15-25.

Çelik, S.E., Özyürek, M., Güçlü, K., Apak R., 2010. Solvent effects on the antioxidant capacity of lipophilic and hydrophilic antioxidants measured by CUPRAC, ABTS/persulphateand FRAP methods. Talanta 81, 1300-1309. 
Chen, Z., Bertin, R., Froldi, G., 2013. EC 50 $_{0}$ estimation of antioxidant activity in DPPH assay using several statistical programs. Food Chem. 138, 414-420.

Chhabra, S.C., Mahunnah, R.L.A., Mshiu, E.N., 1991. Plants used in traditional medicine in Eastern Tanzania. V. Angiosperms (Passifloraceae to Sapindaceae). J. Ethnopharmacol. 33, 143-157.

Chung, Y-C., Chang, C-T., Chao, W-W., Lin, C-F., Chou, S-T., 2002. Antioxidative activity and safety of the $50 \%$ ethanolic extract from red bean fermented by Bacillus subtilis IMR-NK1. J. Agric. Food Chem. 50, 2454-2458.

Corrêa, R.C.G., Souza, A.H.P., Calhelha, R.C., Barros, L., Glamoclija, J.,Sokovic, M., Peralta, R.M., Bracht, A., Ferreira, I.C.F.R., 2015. Bioactive formulations prepared from fruiting bodies and submerged culture mycelia of the Brazilian edible mushroom Pleurotus ostreatoroseus Singer. Food Funct. 6, 2155-2164.

Cuyckens, F., Claeys, M., 2004. Mass spectrometry in the structural analysis of flavonoids. J. Mass Spec. 39, 1-15.

de Pascual-Teresa, S.C., Santos-Buelga, C., Rivas-Gonzalo, J.C., 2000. Quantitative analysis of flavan-3-ols in Spanish foodstuffs and beverages. J. Agric. Food Chem. 48, 5331-5337.

Delgado, M.E., Haza, A.I., García, A., Morales, P., 2009. Myricetin, quercetin, (+)catechin and (-)-epicatechin protect against N-nitrosamines-induced DNA damage in human hepatoma cells. Toxicol. In Vitro 23, 1292-1297.

Embuscado, M.E., 2015. Spices and herbs: Natural sources of antioxidants - a mini review. J. Funct. Foods 18, 811-819.

Fern, K., Fern, A, Morris, R., 2016. Useful Tropical Plants Database. Available on line at http://tropical.theferns.info/ (consulted in January 2016). 
Ferreres, F., Silva, B.M., Andrade, P. B., Seabra, R. M., Ferreira, M.A., 2003. Approach to the study of $C$-glycosyl flavones by ion trap HPLC-PAD-ESI/MS/MS: Application to seeds of quince (Cydonia oblonga). Phytochem. Anal. 14, 352-390.

Fraga, C., 2007. Plant polyphenols: How to translate their in vitro antioxidant actions to in vivo conditions. Int. Union Biochem. Mol. Biol. Life 59, 308-315.

Gardi, C., Bauerova, K., Stringa, B., Kuncirova, V., Slovak, L., Ponist, S., Drafi, F, Bezakova, L., Tedesco, I., Acquaviva, A., Bilotto, S., Russo, G.L., 2015. Quercetin reduced inflammation and increased antioxidant defense in rat adjuvant arthritis. Arch. Biochem. Biophys. 583, 150-157.

Geyid, A., Abebe, D., Debella, A., Makonnen, Z., Aberra F., Teka F., Kebede T., Urga K., Yersaw, K., Biza, T., Mariam, B.H., Guta, M., 2005. Screening of some medicinal plants of Ethiopia for their anti-microbial properties and chemical profiles. J Ethnopharm. 97, 421-427.

Girma, S., Giday, M., Erko, B., Girma, H.M., 2015. Effect of crude leaf extract of Osyrisquadripartita on Plasmodiumberghei in Swiss albino mice. Bio. Med. Central Complem. Altern. Med. 15, 184.

Halliwell, B., 2006. Reactive Species and Antioxidants. Redox biology is a fundamental theme of aerobic life. Plant Physiol. 141, 312-322

Halliwell, B., 2008. Are polyphenols antioxidants or pro-oxidants? What do we learn from cell culture and in vivo studies? Arch. Biochem. Biophys. 476, 107-112.

Halliwell, B., 2009. The wanderings of a free radical. Free Rad. Biol. Med. 46, 531542.

Haza, A.I., Morales, P., 2011. Effects of (+)-catechin and (-)-epicatechin on heterocyclic amines-induced oxidative DNA damage. J. Appl. Toxicol. 31, 53-62. 
Huang, D., Ou, B., Prior, R.L., 2005. The chemistry behind antioxidant capacity assays. J. Agric. Food Chem. 53, 1841-1856.

Ibrahim, M.M., Sahli, A.L., Alaraidh, A.A., Al-Homaidan, I.A., Mostafa, A.A., ELGaaly, G.A., 2015. Assessment of antioxidant activities in roots of Miswak (Salvadora persica) plants grown at two different locations in Saudi Arabia. Saudi J. Biol. Sci. 22, 168-175.

Iwashina, T., López-Saéz, J.A., Kitajima, J., 2008. Flavonoids from Osyri salba. Biochem. System. Ecol. 36, 146-147.

Kashfi, K., 2009. Anti-inflammatory agents as cancer therapeutics. Adv. Pharmacol. 57, $31-89$

Kelbessa, Z.E., Nagappan, R., 2014. Ethnobotanical study of traditional medicinal plants in and around fiche district, Central Ethiopia. Current Research. J. Biol. Sci. 6, 154-167.

Koleva, I.I., van Beek, T.A., Linssen, J.P.H., de Groot, A., Evstatieva, L.N., 2002. Screening of plant extracts for antioxidant activity: A comparative study onthree testing methods. Phytochem. Anal. 13, 8-17.

Kreipl, A.T., Konig, W.A., 2004. Sesquiterpenes from the east African sandalwood Osyris tenuifolia. Phytochem. 65, 2045-2049.

Krishnaiah, D., Sarbatly, R., Nithyanandam, R., 2011. A review of the antioxidant potential of medicinal plant species. Food Bioprod. Proc. 89, 217-233.

Kulkarni, A.P., Aradhya, S.M., Divakar, S., 2004. Isolation and identification of radical scavenging antioxidant - punicalagin from the pith and carpellary membrane of pomegranate fruit. Food Chem. 87, 551-557.

Liao, W., Ning, Z., Chen, L., Wei, Q., Yuan, E., Yang, J., and Ren, J., 2014. Intracellularantioxidant detoxifying effects of diosmetin on 2,2-azobis(2- 
amidinopropane)dihydrochloride (AAPH)-induced oxidative stress through inhibition of reactiveoxygen species generation. J. Agric. Food Chem. 62, 86488654

Marinovic, M.P., Morandi, A.C., Otton, R., 2015. Green tea catechins alone or in combination alter functional parameters of human neutrophils via suppressing the activation of TLR-4/NF $\mathrm{N}_{\mathrm{k}} \mathrm{p} 65$ signal pathway. Toxicol. in Vitro 29, 1766-1778.

Masevhem, N.A., McGaw, L.J., Eloff, J.N., 2015. The traditional use of plants to manage candidiasis and related infections in Venda, South Africa. J. Ethnopharm. $168,364-372$.

Middleton, E., Kandaswami, C., 1992. Effects of flavonoids on immune and Inflammatory cell functions. Biochem. Pharmacol. 43, 1167-1179.

Mulaudzi, R.B., Dhlala, A.R.N, Kulkarni, J.F., Finnie, M.G., VanStaden, J., 2013. Antiinflammatory and mutagenic evaluation of medicinal plants used by Venda people against venereal and related diseases. J. Ethnopharm. 146, 173-179.

Mulaudzi, R.B., Ndhlala, A.R., Kulkarni, M.G., Finnie, J.F., Van Staden J., 2011. Antimicrobial properties and phenolic contents of medicinal plants used by the Venda people for conditions related to venereal diseases. J. Ethnopharm. 135, $330-337$.

Osman, A.M., 2011. Multiple pathways of the reaction of 2,2-diphenyl-1-picrylhydrazyl radical $(\mathrm{DPPH})$ with $(+)$-catechin: Evidence for the formation of a covalent adduct between DPPH and the oxidized form of the polyphenol. Biochem. Biophys. Res. Comm. 412, 473-478.

Ozsoy, N., Can, A., Yanardag, R., Akev, N., 2008. Antioxidant activity of Smilax excelsa L. leaf extracts. Food Chem. 110, 571-583. 
Pokorny, J., Yanishlieva, N., Gordon, M.H., 2001. Antioxidants in food: practical applications. Cambridge: Woodhead Publishing Limited. New York, US, 108109.

Quezel, P., Santa, S., 1963. Nouvelle flore de l'Algérie et des régions désertiques méridionales. CNRS, ed., Paris.

Rached, W., Bennamar, H., Bennaceur, M., Marouf, A., 2010. Screening of the antioxidant potential of some Algerian indigenous plants. J. Biol. Sci. 10, 17273048 .

Rodgers, E.H., Grant, M.H. (1998). The effect of the flavonoids, quercetin, myricetin and epicatechin on the growth and enzyme activities of MCF7 human breast cancer cells. Chem.-Biol. Interact. 116, 213-228.

Roriz, C.L., Barros, L., Carvalho, A.M., Santos-Buelga, C., Ferreira, I.C.F.R., 2014. Pterospartum tridentatum, Gomphrena globosa and Cymbopogon citratus: A phytochemical study focused on antioxidant compounds. Food Res. Int. 62, 684693.

Santos-Buelga, C., García-Viguera, C., Tomás-Barberán, F.A., 2003. On-line identification of flavonoids by HPLC coupled to diode array detection. In, Methods in polyphenol analysis. Royal Society of Chemistry, Cambridge, UK. $92-127$.

Santos-Buelga, C., González-Paramás, A.M., 2014. Strategies in the analysis of flavonoids. In, Handbook of Chemical and Biological Plant Analytical Methods, First Edition. Edited by K. Hostettmann, H. Stuppner, A. Marston and S. Chen. John Wiley \& Sons, Ltd.; pp. 543-568. 
Semenya, S.S., Maroyi, A., 2012. Medicinal plants used by the Bapedi traditional healers to treat diarrhoea in the Limpopo Province, South Africa. J. Ethnopharm. $144,395-401$.

Shahidi, F., Zhong, Y., 2005. Lipid Oxidation: Measurement Methods. Bailey's Industrial Oil and Fat Products, Sixth Edition, Six Volume Set. Edited by Fereidoon Shahidi. Copyright, John Wiley and Sons, Inc.

Shen, S.C., Lee, W.R., Lin, H.Y., Huang, H.C., Ko, C.H., Yang, L.L., Chen, Y.C., 2002. In vitro and in vivo inhibitory activities of rutin, wogonin, and quercetin on lipopolysaccharide-induced nitric oxide and prostaglandin E2 production. Eur. J. Pharmacol. 446, 187-194.

Shinmoto, H., Dosako, S., Nakajima, I., 1992. Antioxidant activity of bovine lactoferrin on iron/ascorbate induce lipid peroxidation. Biosci. Biotechnol. Biochem. 56, 2079-2080.

Singh, D.H., Batish, D., Kohli, R.K., 2005. Handbook of Sustainable Weed Management. Haworth Press ed., Binghamton, New York. 721.

Singh, R., Singh, S., Kumar, S., Arora, S., 2007. Evaluation of antioxidant potential of ethyl acetate extract/fractions of Acacia auriculiformis A. Cunn. Food Chem. Toxicol. 45, 1216-1223.

Tepe, B., Sokmen, M., Akpulat, H. A., Daferera, D., Polissiou, M., Sokmen, A., 2005. Antioxidative activity of the essential oils of Thymus sipyleus subsp Sipyleusvar. sipyleus and Thymus sipyleus subsp. sipyleus var. rosulans. J. Food Eng. 66, 447454.

Tiwari, A.K., 2001. Imbalance in antioxidant defence and human diseases: Multiple approach of natural antioxidants therapy. Curr. Sci. 81, 1179-1187. 
Van Vuuren, S.F., Viljoen, A.M., 2006. The in vitro antimicrobial activity of toothbrush sticks used in Ethiopia. South Afri. J. Bot. 72, 646-648.

Wang, Y., Chen, P., Tang, C., Wang, Y., Li, Y., Zhang, H., 2014. Antinociceptive and anti-inflammatory activities of extract and two isolated flavonoids of Carthamus tinctorius L. J. Ethnopharm. 151, 944-950.

Wang, Y.C., Huang, K.-M., 2013). In vitro anti-inflammatory effect of apigenin in the Helicobacter pylori-infected gastric adenocarcinoma cells. Food Chem. Toxicol. $53,376-383$.

Yanishlieva-Maslarova, N.V., 2001). Inhibiting oxidation. In: Pokorny, J., Yanishlieva, N., Gordon, M.H. (Eds.), Antioxidants in Food: Practical Applications. Woodhead Publishing Limited, Cambridge, pp. 22-70.

Yeboah, E.M.O., Majinda, R.R.T., Kadziola, A., Muller, A. (2010). Dihydro- $\beta$ agarofuransesquiterpenes and pentacyclic triterpenoids from the root bark of Osyrislanceolata. J. Nat. Prod. 73, 1151-1155. 
Table 1. Retention time (Rt), wavelengths of maximum absorption in the visible region $\left(\lambda_{\max }\right)$, mass spectral data, identification and quantification of phenolic compounds in O. quadripartita leaves (mean $\pm \mathrm{SD}$ ).

\begin{tabular}{|c|c|c|c|c|c|c|c|c|}
\hline \multirow{2}{*}{ Compounds } & \multirow{2}{*}{$\operatorname{Rt}(\min )$} & \multirow{2}{*}{$\begin{array}{l}\lambda_{\max } \\
(\mathrm{nm})\end{array}$} & \multirow{2}{*}{$\begin{array}{c}\text { Pseudomolecular } \\
\text { ion } \\
{[\mathrm{M}-\mathrm{H}]^{-}(\mathrm{m} / \mathrm{z})}\end{array}$} & \multirow{2}{*}{$\begin{array}{l}\mathrm{MS}^{2} \\
(\mathrm{~m} / z)\end{array}$} & \multirow{2}{*}{ Tentative identification } & \multicolumn{3}{|c|}{$\begin{array}{l}\text { Quantification } \\
\quad(\mathrm{mg} / \mathrm{g})\end{array}$} \\
\hline & & & & & & $\begin{array}{c}\text { Aqueous } \\
\text { extract }\end{array}$ & $\begin{array}{l}\text { Ethyl acetate } \\
\text { fraction }\end{array}$ & $\begin{array}{l}\text { Butanolic } \\
\text { fraction }\end{array}$ \\
\hline 1 & 5.2 & 278 & 865 & $739(5), 713(5), 695(13), 577(17), 575(12), 425(17), 407(30), 289(13), 287(40)$ & $\begin{array}{l}\text { B-type (epi)catechin trimer [suggested } \\
\text { identity: trimer } \mathrm{C} 2(\mathrm{C}-4,8-\mathrm{C}-4,8-\mathrm{C})]\end{array}$ & $2.6 \pm 0.05$ & $3.4 \pm 0.3$ & $5.1 \pm 0.1$ \\
\hline 2 & 5.4 & 280 & 865 & 739(9),713(13),695(22),577(30),575(26),425(17),407(39),289(17),287(26) & $\begin{array}{l}\text { B-type (epi)catechin trimer [suggested } \\
\text { identity: trimer EC-4,8-C-4,8-C)] }\end{array}$ & $4.0 \pm 0.2$ & $3.77 \pm 0.01$ & $4.5 \pm 0.1$ \\
\hline 3 & 5.9 & 280 & 577 & 451(23),425(31),407(100),289(62),287(8) & Procyanidin dimer B3 (C-4,8-C) & $5.02 \pm 0.3$ & $11.32 \pm 0.04$ & $2.1 \pm 0.1$ \\
\hline 4 & 6.0 & $260,296 \mathrm{sh}$ & 153 & $109(100)$ & Protocatechuic acid & nd & $1.5 \pm 0.2$ & nd \\
\hline 5 & 6.7 & 280 & 577 & $451(15), 425(46), 407(100), 289(50), 287(9)$ & Procyanidin dimer B1 (EC-4,8-C) & $11.1 \pm 0.2$ & $100.5 \pm 0.3$ & $8.7 \pm 0.2$ \\
\hline 6 & 6.9 & 280 & 865 & 739(5),713(5),695(16),577(31),575(10),425(15),407(38),289(23),287(15) & B-type (epi)catechin trimer & $12.1 \pm 0.4$ & $74 . \pm 1$ & $10.8 \pm 0.5$ \\
\hline 7 & 7.3 & 280 & 865 & $739(8), 713(7), 695(20), 577(45), 575(8), 425(20), 407(30), 289(11), 287(25)$ & B-type (epi)catechin trimer & nd & nd & $6.6 \pm 0.2$ \\
\hline 8 & 7.8 & 280 & 289 & 245(42),203(36),187(27),161(13),137(28) & $(+)$-Catechin $(\mathrm{C})$ & $10.1 \pm 0.2$ & $110.5 \pm 0.3$ & $12.8 \pm 0.3$ \\
\hline 9 & 8.4 & 280 & 577 & $451(13), 425(38), 407(100), 289(48), 287(15)$ & Procyanidin dimer B4 (E-4,8-EC) & $5.7 \pm 0.1$ & $30 \pm 1$ & $4.5 \pm 0.2$ \\
\hline 10 & 9.3 & 278 & 435 & $289(30), 271(11), 245(6), 203(8), 161(5), 137(100), 125(49)$ & Epicatechin- $O$-rhamnoside & $6.8 \pm 0.3$ & $67.1 \pm 0.4$ & $12.7 \pm 0.5$ \\
\hline 11 & 10.4 & 280 & 577 & $451(18), 425(82), 407(91), 289(100), 287(18)$ & Procyanidin dimer B2 (EC-4,8E-C) & $1.18 \pm 0.02$ & $21.7 \pm 0.2$ & $7.7 \pm 0.2$ \\
\hline 12 & 10.9 & 278 & 289 & 245(39),203(30),187(17),161(13),137(17) & (-)-Epicatechin (EC) & $1.25 \pm 0.01$ & $21 \pm 1$ & $0.71 \pm 0.01$ \\
\hline 13 & 11.1 & 338 & 593 & $503(12), 473(20), 383(40), 365(8), 353(40), 325(14), 297(12), 283(13)$ & Apigenin-6,8-di-C-glucoside (vicenin-2) & $0.4 \pm 0.01$ & nd & $1.2 \pm 0.3$ \\
\hline 14 & 12.5 & 280 & 577 & $451(20), 425(18), 407(5), 289(54)$ & Procyanidin dimer B7 (EC-4,6-C) & $1.4 \pm 0.05$ & $12.4 \pm 0.3$ & $2.5 \pm 0.1$ \\
\hline 15 & 14.1 & 336 & 563 & $545(3), 503(13), 473(13), 443(13), 383(22), 353(48), 297(13)$ & Apigenin-6- $C$-hexoside-8- $C$-pentoside & $0.32 \pm 0.01$ & nd & $0.75 \pm 0.01$ \\
\hline
\end{tabular}




\begin{tabular}{|c|c|c|c|c|c|c|c|c|}
\hline 16 & 14.4 & 280 & 577 & $451(15), 425(31), 407(92), 289(69), 287(23)$ & Procyanidin dimer B8 (C-4,6-EC) & nd & $9.7 \pm 0.5$ & nd \\
\hline 17 & 14.9 & 336 & 563 & $545(3), 503(7), 473(7), 443(12), 383(35), 353(30), 297(12)$ & Apigenin-6-C-hexoside- $8-C$-pentoside & $0.72 \pm 0.04$ & nd & $1.87 \pm 0.04$ \\
\hline 18 & 15.2 & 336 & 563 & $545(3), 503(4), 473(7), 443(20), 383(24), 353(26), 297(5)$ & Apigenin-6-C-hexoside- 8 - $C$-pentoside & $0.87 \pm 0.01$ & nd & $1.9 \pm 0.1$ \\
\hline 19 & 15.3 & 280 & 865 & 739(29),713(5),695(29),577(18),575(29),425(18),407(41),289(29),287(18) & B-type (epi)catechin trimer & nd & $6.7 \pm 0.5$ & nd \\
\hline 20 & 15.7 & 358 & 755 & $301(100)$ & Quercetin- $O$-dideoxyhexosyl-hexoside & $0.50 \pm 0.02$ & nd & $1.62 \pm 0.01$ \\
\hline 21 & 16.4 & 280 & 577 & $451(5), 425(18), 407(12), 289(35), 287(12)$ & Procyanidin dimer B5 (EC-4,6-EC) & nd & $6.9 \pm 0.2$ & nd \\
\hline 22 & 16.5 & 338 & 563 & $545(3), 503(6), 473(19), 443(16), 383(12), 353(13), 297(6)$ & Apigenin-6-C-hexoside-8-C-pentoside & $0.15 \pm 0.01$ & nd & $0.56 \pm 0.03$ \\
\hline 23 & 16.7 & 336 & 563 & $443(21), 383(11), 353(12), 297(12)$ & Apigenin-6-C-hexoside- 8 - $C$-pentoside & $0.20 \pm 0.01$ & nd & $0.58 \pm 0.02$ \\
\hline 24 & 17.2 & 312 & 163 & $119(100)$ & $p$-Coumaric acid & $0.050 \pm 0.001$ & $1.9 \pm 0.1$ & nd \\
\hline 25 & 18.4 & $282,324 \mathrm{sh}$ & 433 & $271(100)$ & Naringenin- $O$-hexoside & nd & $1.10 \pm 0.01$ & nd \\
\hline 26 & 19.2 & 358 & 609 & $301(100)$ & Quercetin-3-O-rutinoside & $33.8 \pm 0.1$ & $17.70 \pm 0.02$ & $36.0 \pm 0.1$ \\
\hline 27 & 20.6 & 352 & 463 & $301(100)$ & Quercetin-3-O-glucoside & $0.14 \pm 0.01$ & $0.68 \pm 0.01$ & $0.12 \pm 0.01$ \\
\hline \multirow[t]{7}{*}{28} & 22.7 & 348 & 593 & $285(100)$ & Kaempferol-3-O-rutinoside & $1.03 \pm 0.07$ & $2.40 \pm 0.01$ & $1.90 \pm 0.05$ \\
\hline & & & & & Total phenolic acids & $0.05 \pm 0.001 \mathrm{~b}$ & $3.4 \pm 0.3 \mathrm{a}$ & nd \\
\hline & & & & & Total flavan-3-ols & $62 \pm 2 \mathrm{c}$ & $479 \pm 5 \mathrm{a}$ & $79 \pm 2 b$ \\
\hline & & & & & Total flavonols & $35.48 \pm 0.02 \mathrm{~b}$ & $20.78 \pm 0.02 \mathrm{c}$ & $39.67 \pm 0.02 \mathrm{a}$ \\
\hline & & & & & Total flavones & $2.7 \pm 0.1 \mathrm{~b}$ & nd & $6.9 \pm 0.1 \mathrm{a}$ \\
\hline & & & & & Total flavanones & nd & $1.10 \pm 0.01$ & nd \\
\hline & & & & & Total phenolic compounds & $100 \pm 2 b$ & $504 \pm 5 \mathrm{a}$ & $125 \pm 2 b$ \\
\hline
\end{tabular}

Catechin (C), epicatechin (EC) and not detected (nd). For the row of the total phenolic compounds different letters mean significant differences between $O$. quadripartita extract and fractions $(\mathrm{p}<0.05)$. 
Table 2. Antioxidant activity and NO formation inhibition capacity of $O$. quadripartita leaves.

\begin{tabular}{|c|c|c|c|c|}
\hline & Aqueous extract & Ethyl acetate fraction & Butanolic fraction & Positive control* \\
\hline \multicolumn{5}{|c|}{ Antioxidant activity $\left(\mathrm{EC}_{50}\right.$ values, $\left.\mu \mathrm{g} / \mathrm{mL}\right)$} \\
\hline DPPH scavenging activity & $12.4 \pm 0.4^{\mathrm{a}}$ & $5.2 \pm 0.4^{\mathrm{c}}$ & $10.3 \pm 0.3^{\mathrm{b}}$ & $42 \pm 1$ \\
\hline Reducing power & $6.24 \pm 0.03^{\mathrm{a}}$ & $2.5 \pm 0.1^{\mathrm{c}}$ & $4.4 \pm 0.1^{\mathrm{b}}$ & $41 \pm 1$ \\
\hline$\beta$-carotene bleaching inhibition & $4.6 \pm 0.1^{\mathrm{a}}$ & $3.4 \pm 0.3^{\mathrm{c}}$ & $3.8 \pm 0.1^{\mathrm{b}}$ & $18 \pm 1$ \\
\hline TBARS inhibition & $2.1 \pm 0.1^{\mathrm{a}}$ & $1.28 \pm 0.05^{\mathrm{c}}$ & $1.41 \pm 0.01^{\mathrm{b}}$ & $23 \pm 1$ \\
\hline \multicolumn{5}{|c|}{ Anti-inflammatory activity $\left(\mathrm{EC}_{50}\right.$ values, $\left.\mu \mathrm{g} / \mathrm{mL}\right)$} \\
\hline Nitric oxide (NO) production & $211 \pm 4^{\mathrm{a}}$ & $78 \pm 7^{\mathrm{c}}$ & $194 \pm 5^{\mathrm{b}}$ & $16 \pm 1$ \\
\hline
\end{tabular}

*Trolox and dexamethasone for antioxidant and anti-inflammatory activities, respectively. The antioxidant activity was expressed as EC 50 values (mean \pm SD), what means that higher values correspond to lower reducing power or antioxidant potential. $\mathrm{EC}_{50}$ : extract concentration corresponding to $50 \%$ of antioxidant activity or 0.5 of absorbance in reducing power assay. Results of anti-inflammatory activity are expressed in $\mathrm{EC}_{50}$ values: sample concentration providing $50 \%$ of inhibition of nitric oxide (NO) production. In each row different letters mean significant differences between $O$. quadripartite extract and fractions ( $\mathrm{p}<0.05)$. 
Table 3. Cytotoxic properties of $O$. quadripartita leaves in human tumor cell lines and non-tumor liver primary cells.

\begin{tabular}{|c|c|c|c|c|}
\hline & Aqueous extract & Ethyl acetate fraction & Butanolic fraction & Ellipticine \\
\hline \multicolumn{5}{|c|}{ Human tumor cell lines $\left(\mathrm{GI}_{50}\right.$ values, $\left.\mu \mathrm{g} / \mathrm{mL}\right)$} \\
\hline MCF-7 (breast carcinoma) & $199 \pm 10^{\mathrm{a}}$ & $114 \pm 8^{\mathrm{b}}$ & $200 \pm 3^{\mathrm{a}}$ & $0.91 \pm 0.04$ \\
\hline NCI-H460 (non-small cell lung cancer) & $308 \pm 18^{\mathrm{b}}$ & $265 \pm 14^{\mathrm{c}}$ & $356 \pm 19^{\mathrm{a}}$ & $1.03 \pm 0.09$ \\
\hline HeLa (cervical carcinoma) & $87 \pm 9^{\mathrm{b}}$ & $154 \pm 2^{\mathrm{a}}$ & $153 \pm 9^{\mathrm{a}}$ & $1.91 \pm 0.06$ \\
\hline HepG2 (hepatocellular carcinoma) & $46 \pm 1^{\mathrm{c}}$ & $146 \pm 13^{b}$ & $167 \pm 1^{\mathrm{a}}$ & $1.14 \pm 0.21$ \\
\hline \multicolumn{5}{|l|}{ Non-tumor cells (GI ${ }_{50}$ values, $\mu \mathrm{g} / \mathrm{mL}$ ) } \\
\hline PLP2 (porcine liver primary cells) & $>400$ & $>400$ & $>400$ & $3.22 \pm 0.67$ \\
\hline
\end{tabular}

$\mathrm{GI}_{50}$ values (mean $\pm \mathrm{SD}$ ) correspond to the sample concentration achieving $50 \%$ of growth inhibition in human tumor cell lines or in liver primary culture PLP2. In each row different letters mean significant differences between $O$. quadripartite extract and fractions $(\mathrm{p}<0.05)$. 


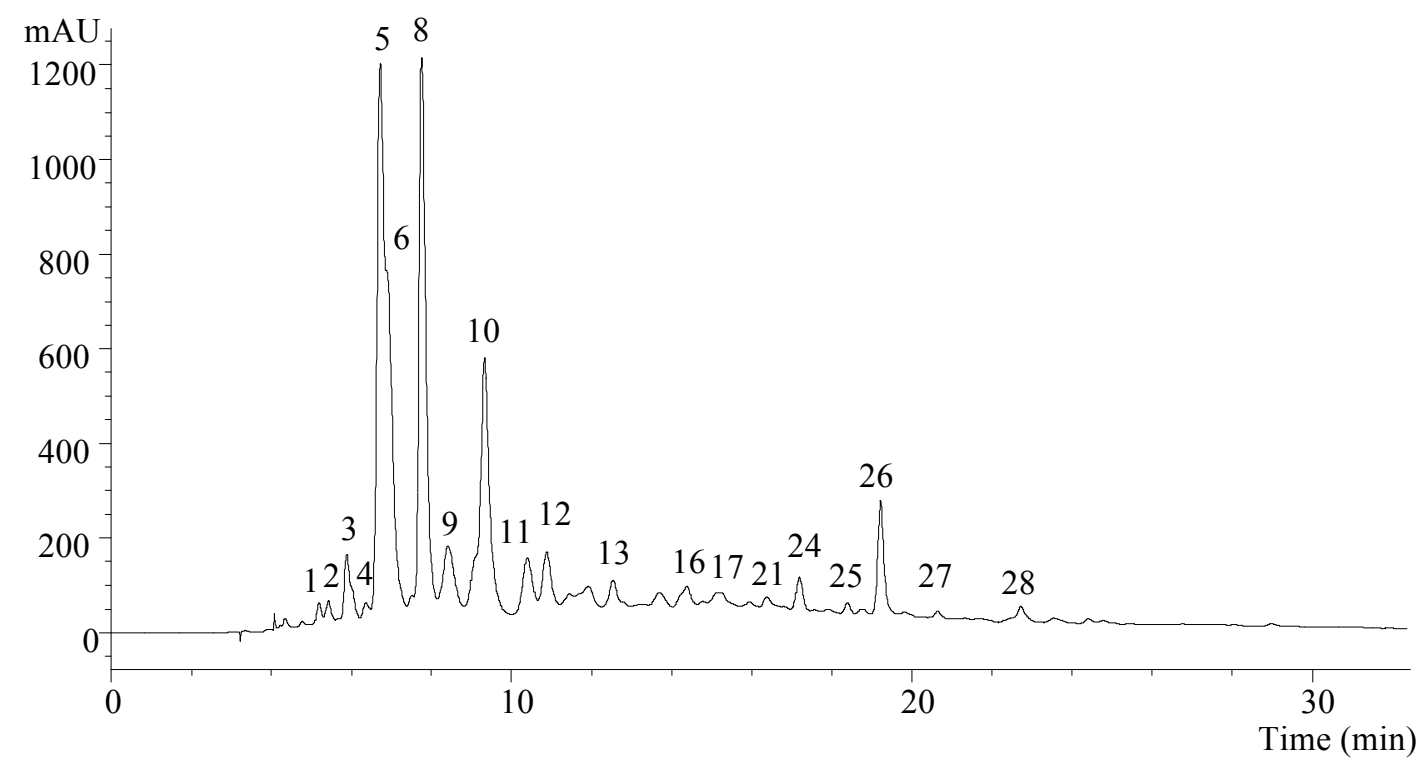

Figure 1. Phenolic compounds profile of n $O$. quadripartite ethyl acetate fraction, recorded at $280 \mathrm{~nm}$. 